\title{
Acute non-infectious arthritis of the hip in patients with rheumatoid arthritis*
}

\author{
JAMES T HALLA ${ }^{1}$ AND JOE G HARDIN ${ }^{2}$ \\ From ${ }^{1} 1927$ Pine Street, Abilene, TX 79601, USA; and ${ }^{2} 2451$ Fillingim Street, Mobile, AL 36617, USA
}

SUMMARY Five patients with rheumatoid arthritis and no previous hip joint disease developed an acute disabling arthritis in one hip joint. Roentgenograms were negative and synovial fluid from the hip joint was inflammatory, but no crystals were seen and cultures were negative. Four of the five patients responded rapidly to intra-articular corticosteroids, and none of the five has had further hip joint symptoms during a mean follow up period of two years.

Key words: transient synovitis.

Hip joint involvement in patients with rheumatoid arthritis (RA) may be defined clinically, but most published observations addressing the problem have focused on roentgenographic abnormalities; by this definition, hip joint involvement has been recognised in $30-75 \%$ of patients with $\mathrm{RA}^{1-7}$ Acute flares of articular synovitis are a well recognised phenomenon in RA, though an acute flare of limited distribution should raise the question of a superimposed infectious process. ${ }^{8}$ Flares in the hip joint in patients with RA could be assumed to occur as often as flares in other joints, but no previously published report has specifically addressed this issue. Because of the apparent rarity, unique clinical features, and dramatic presentation of this phenomenon we report our experience with five cases of acute hip joint arthritis in patients with RA.

\section{Case reports}

Over a five year period 400 patients with definite or classical RA according to the criteria of the American Rheumatism Association were evaluated and followed up. During this period five of these patients developed an acute hip joint arthritis; their clinical and laboratory findings are summarised in Table 1. All five were receiving regular nonsteroidal anti-inflammatory drug and disease modifying agent therapy, and all were considered to be responding to therapy at the time the acute hip joint

Accepted for publication 13 January 1987.

Correspondence to Dr Joe G Hardin, 2451 Fillingim Street, Mobile, AL 36617, USA.

${ }^{*}$ Presented in part at the southeastern regional meeting of the American Rheumatism Association, Savannah, GA, December 1985. arthritis began. None of the five patients had a previous history of symptoms or previous physical findings suggesting hip joint involvement.

For no apparent reason all five patients developed, over a 36 hour period, a severe and disabling pain in the vicinity of one hip (left in three, right in two), and none was able to tolerate weight bearing on the affected side. Two of the patients also had a polyarticular worsening of their arthritis and two had a flare in one other large joint (knee and wrist), but the hip pain was the overwhelming chief complaint in all.

None of the patients was febrile. All had marked pain on motion and apparent limitation of motion of the affected hip. Bilateral hip joint roentgenograms were normal in all patients. Synovial fluid (4-14 ml) was obtained from all five affected hip joints, and the total white blood cell counts are detailed in Table 1. All fluids showed a predominance of polymorphonuclear leucocytes and none contained crystals. Gram's stain and routine cultures of all fluids were negative. In two patients simultaneous knee joint synovial fluids were obtained and both had a lower total white blood cell count than that of the hip joint fluid $\left(6.6 \times 10^{9} / 1 v 26 \times 10^{9} / 1\right.$ and $\left.21 \times 10^{9} / 1 v 37 \times 10^{9} / 1\right)$.

Four patients were treated with hip joint intraarticular corticosteroids, and their hip joint symptoms abated within 24 hours; the fifth patient improved gradually over several days with no specific therapy. The five patients have been followed up for up to four years (mean of two years) with no further hip symptoms and continued normal hip joint roentgenograms. All have had occasional flares in other joints, however. 
Table 1 Summary of clinical and laboratory findings in patients with RA and acute arthritis of the hip)

\begin{tabular}{|c|c|c|c|c|c|}
\hline & \multicolumn{5}{|c|}{ Patient Vo } \\
\hline & 1 & 2 & 3 & 4 & 5 \\
\hline Age (vears) & 61 & 71 & 68 & 24 & 45 \\
\hline Sex & $\mathrm{F}$ & $\mathrm{M}$ & $\mathrm{F}$ & $\mathrm{F}$ & $\mathrm{F}$ \\
\hline Discase duration (ycars) & 6 & 10 & 14 & 14 & 0.5 \\
\hline Rheumatoid factor (latex) & Negative & $1 / 640$ & $1 / 160$ & $1 / 160$ & Negative \\
\hline Westergren sedimentation rate $(\mathrm{mm} / \mathrm{h})$ & 48 & 50 & 125 & $10(1)$ & 49 \\
\hline Subcutancous nodules & No & No & No & Yes & $\left.N_{0}\right)$ \\
\hline Peripheral joint erosions & No & Yes & Yes & Ni & $\mathrm{No}$ \\
\hline \multicolumn{6}{|l|}{ Hip joint synovial fluid white } \\
\hline cell count/litre & $71 \times 10^{\prime \prime}$ & $46 \times 10^{16}$ & $26 \times 10^{\prime \prime}$ & $37 \times 10^{11}$ & $55 \times 10^{\prime \prime}$ \\
\hline
\end{tabular}

\section{Discussion}

The five patients reported above represent only $1 \%$ of a population of patients with RA followed up for approximately 1200 patient years; consequently this phenomenon can be considered rare. None of these 400 patients has developed an infectious arthritis of the hip joint, so that acute non-infectious arthritis in patients with RA seems to be more common than septic arthritis at that site. This phenomenon appears to be different from flares of RA in other joints. It may occur with no previous or subsequent evidence of hip joint synovitis, and it seems to be more dramatic and more disabling than flares at other sites. Although the inflammatory reaction appears to be relatively intense, the prognosis for rapid recovery is quite good. The natural history of this phenomenon cannot be determined from our patients since four of the five received and responded to intra-articular corticosteroids. One patient did not receive this therapy because of a strong suspicion of septic arthritis, but even in that patient recovery was relatively rapid.

Though occurring in patients with RA, the phenomenon described above is remarkably similar to an idiopathic syndrome reported in children and adults under the names of 'transient synovitis of the hip' and 'irritable hip', though not all of the synovial fluids from these cases have been inflammatory. ${ }^{9-11}$ In our patients it must be assumed that the hip joint arthritis was a flare of the RA, and simultaneous flares in other joints in four of our five patients support this notion.
In summary, acute non-infectious arthritis of of hip in patients with RA is a rare, benign, but dramatic phenomenon; it seems, however, to more common than septic arthritis, which it can mimic (and which must be excluded).

\section{References}

1 Resnick D. Niwayama G. Rheumatoid arthritis. In: Resnick Niwayama G. eds. Diagnosis of bone and joint disorders wh emphasis on articular abnormalities. Philadelphia: Saund్ㅀ. 1981: 906-1007

2 Harris E D Jr. Rheumatoid arthritis: the clinical spectrum. Kelley W N, Harris E D Jr. Ruddy S. Sledge C B, eब. Textbook of rheumatology. Philadelphia: Saunders, 19\% 915-50.

3 Duthic R B. Harris C M. A radiographic and clinical survey the hip joint in sero-positive rheumatoid arthritis. Acta Orthe Scand 1969: 40: 346-64.

4 Bossingham D H. Schorn D. Morgan G W. Mowat A ל̂. Progression of hip discase in rheumatoid arthritis. Rheumal Rehabil 1978; 17: 170-8.

5 Hastings D E. Parker S M. Protrusio acetabuli in rheumat arthritis. Clin Orthop 1975; 108: 76-83.

6 Glick E N. Mason R M. Wenley W G. Rheumatoid arthr@is affecting the hip joint. Ann Rheum Dis 1963: 22: 416-23.

7 Halla $J$ T. Hardin J G. The prevalence and nature of $\underline{\text { pp }}$ involvement in rheumatoid arthritis (RA): a private practice experience. Arthritis Rheum 1986; 29: S41

8 Kraft S M. Panush R S. Longley S. Unrecognized staphyloc $\frac{0}{-2}-$ cal pyarthrosis with rheumatoid arthritis. Semin Arthrixis Rheum 1985: 196-201.

9 Adams J A. Transient synovitis of the hip joint in childreo. J Bone Joint Surg /Br/ 1963; 45B: 471-6.

10 Sharwood P F. The irritable hip syndrome in children. CA long-term follow-up. Acta Orthop Scand 1981; 52: 633-8.

11 Dzioba R B, Barrington T W. Transient monoarticular synogyitis of the hip joint in adults. Clin Orthop 1977: 126: 190-2. 